УДК 621.311.001.57(063)

O.O. Закладний, канд. техн. наук, доцент, ORCID 0000-0003-2813-3692

B.B. Прокопенко, канд. техн. наук, доцент, ORCID 0000-0002-5518-5802

Національний технічний університет України «Київський політехнічний інститут імені Ігоря Сікорського»

\title{
УЗАГАЛЬНЕНИЙ ПОКАЗНИК ЕНЕРГЕТИЧНОЇ ЕФЕКТИВНОСТІ ЕЛЕКТРОПРИВОДА
}

У статті розглядаються методичні засади визначення узагальненого показника як критерію ефективності процесу електромеханічного перетворення енергії електроприводом, використання якого необхідне для енергетичної оптимізації електропривода. Наведено баланс потужностей потоків енергії для енергетичного каналу електропривода, ККД послідовного енергетичного каналу та приклад розрахунку узагальненого показника енергоефективності енергетичного каналу електропривода для статичних режимів двигуна постійного струму незалежного збудження.

Ключові слова: енергозбереження, показник енергоефективності, електропривод, коєфіцієнт корисної дії, електричний баланс.

Вступ. На даний час для реалізації одного i того ж технологічного процесу, є можливість застосування різних технічних рішень в кінематиці виконавчих механізмів, у структурній і принциповій схемах побудови систем автоматизованого електроприводу, а також алгоритмах та принципах їх управління. При всьому різноманітті технічних рішень з'являється потреба в адекватній оцінці і порівняльній характеристиці кожного з них, в першу чергу - за показником енергетичної ефективності.

Аналіз попередніх досліджень. Оцінювання енергоефективності електропривода є комплексним завданням 3 великою кількістю характеристик i факторів, що на нього впливають (механічне навантаження, якість напруги живлення, технічний стан, умови навколишнього середовища, якість технічного обслуговування тощо). Від правильної оцінки енергетичної ефективності електропривода залежать багато відповідальних рішень - технічні, економічні, кон'юнктурні. Тим часом традиційні критерії асинхронного електроприводу - ККД і $\cos \varphi$, не завжди дозволяють належним чином оцінити енергетичні процеси в електроприводі. Труднощі при їх використанні виникають і при вирішенні завдань енергозбереження в електроприводі. ККД і $\cos \varphi$ характеризують енергетичний процес, пов'язаний 3 втратами, ККД - перетворення, $\cos \varphi$ - споживання. Але вони мають різні визначальні співвідношення і фізичний зміст. Тому оптимізувати процес доводиться за цими показниками окремо. Порушується спільність оцінки, не кажучи вже про відступ від одного з основних принципів системного підходу оптимальність частин не означає оптимальності цілого [1].

При виведенні узагальненого показника енергетичної ефективності розглядаємо нерозгалуджений енергетичний канал (рис.1), що складається 3 розподільної мережі, силових передавальноперетворювальних елементів, робочого органу, технологічного об'єкта. Структурну схему енергетичного каналу електропривода зображено на рис. 1 [2].

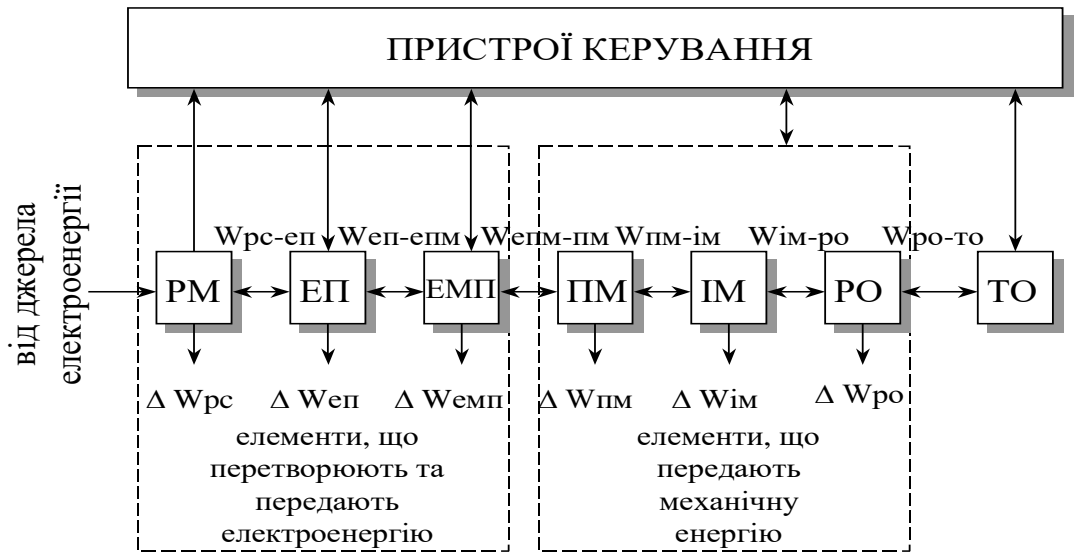

Рисунок 1 - Структура енергетичного каналу електропривода (РМ - розподільна мережа, ЕП електричний перетворювач, ЕМП - електромеханічний перетворювач, ПМ - передавальний механізм, ВМ - виконавчий механізм, РО - робочий орган, ТО -технологічний об’єкт (вантаж))

(C) О.О. Закладний, В.В. Прокопенко, 2017 


\section{ISSN 1813-5420 (Print). Енергетика: економіка, технології, екологія. 2017. № 4}

Процес передачі і перетворення енергії в силовому каналі супроводжується іiі частковою втратою в кожному з елементів $(\Delta W)$ незалежно від напрямку іiї передачі. В остаточному підсумку втрати енергії виділяються у вигляді теплоти.

Всі елементи енергетичного каналу здатні накопичувати енергію в тому чи іншому вигляді в залежності від типу елемента:

- на індуктивностях накопичується енергія магнітного поля;

- на ємностях - енергія електричного поля;

- на пружних елементах і піднятих над землею масах - потенційна механічна енергія;

- на обертових і масах, що лінійно рухаються, - кінетична енергія [3].

Складемо баланс потужностей потоків енергії для енергетичного каналу електропривода 3 урахуванням кінетичної енергії мас, що рухаються, вважаючи, що зміна потенціальної енергії в системі не відбувається

$$
P_{\mathrm{e}}=\sum_{i} J_{i} \omega_{i} \frac{d \omega_{i}}{d t}+\sum_{j} m_{j} V_{j} \frac{d V}{d t}+\sum_{k} \Delta P_{k}+M \omega+F V,
$$

де $P_{\mathrm{e}}$ - електрична потужність потоку енергії між джерелом електроенергії і розподільною ділянкою мережі; $\sum_{i} J_{i} \omega_{i} \frac{d \omega_{i}}{d t}$ i $\sum_{j} m_{j} V_{j} \frac{d V_{j}}{d t}-$ потужності, що виникають у динамічних режимах і пов'язані зі зміною кінетичної енергії обертових мас, що лінійно рухаються; $\sum_{k} \Delta P_{k}$ - сумарні втрати потужності у всіх елементах силового кола; $M \omega, F V$ - потужності механічної енергії, пов'язані з обертальним і поступальним рухом.

Складові рівняння можуть мати різні поєднання рівнів, напрямків енергій і знаків, визначаючи тим самим різноманіття енергетичних станів енергетичного каналу, розмаїтість режимів його роботи. Згорнемо структурну схему привода з урахуванням рівняння балансу потужностей потоків енергії (рис. 2) [4].

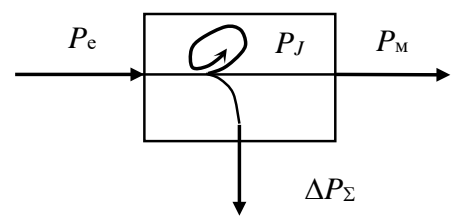

Рисунок 2 - Структурна схема привода з урахуванням рівняння балансу потужностей потоків енергії

Показані позитивні напрямки потоків потужності: $P_{\mathrm{e}^{-}}$електричної потужності; $P_{\mathrm{M}^{-}}$механічної потужності; $P_{J}$ - потужності, пов'язаної зі зміною запасу кінетичної енергії механічної частини; $\Delta P_{\Sigma}$ сумарної потужності втрат.

Кожна зі складових потужності має самостійне значення для аналізу енергетики електропривода. Так, $P_{\mathrm{e}}$ і $\int P_{\mathrm{e}} d t$ - характеризують відповідно витрати потужності й енергії; $P_{\mathrm{M}} \mathrm{i} \int P_{\mathrm{M}} d t-$ механічну потужність і корисну роботу; $\Delta P_{\Sigma}$ i $\int \Delta P_{\Sigma} d t$ - потужність втрати і енергію процесу нагрівання елементів силового каналу.

Коефіцієнт корисної дії визначається як відношення корисної роботи (енергії) на виході пристрою до витраченої енергії на вході

$$
\eta=\frac{W_{\text {кор }}}{W_{\text {вит }}}
$$

Якщо робота пристрою оцінюється за період часу, протягом якого потужності на виході і вході постійні, то ККД

$$
\eta=\frac{P_{\text {кор }}}{P_{\text {вит }}}
$$

При змінному характері навантаження за цикл роботи $t_{L}$ значення ККД [5] 


$$
\eta=\frac{\int_{0}^{t_{\text {и }}} P_{\text {кор }} d t}{\int_{0}^{t_{\text {ч }}} P_{\text {кор }} d t+\int_{0}^{t_{\text {ч }}} \Delta P_{\Sigma} d t} .
$$

Для послідовного енергетичного каналу вихід попереднього елемента ( $\left.P_{\text {кор }}\right) \in$ входом наступного ( $\left.P_{\text {вит }}\right)$, тому ККД визначається добутком

$$
\eta_{\Sigma}=\prod_{i=1}^{n} \eta_{i}
$$

Визначення енергетичного стану електропривода здійснюється порівнянням фактичних параметрів 3 їх еталонними значеннями [6].

Недостатність урахування за допомогою ККД властивостей електропривода лише як перетворювача енергії і неврахування характеристик як ії споживача спричиняє потребу розробки нових підходів до процесів енергоспоживання і енерговикористання [7].

Матеріал і результати досліджень. Для цього представимо енергетичний канал у вигляді послідовно сполучених елементів (рис. 3).

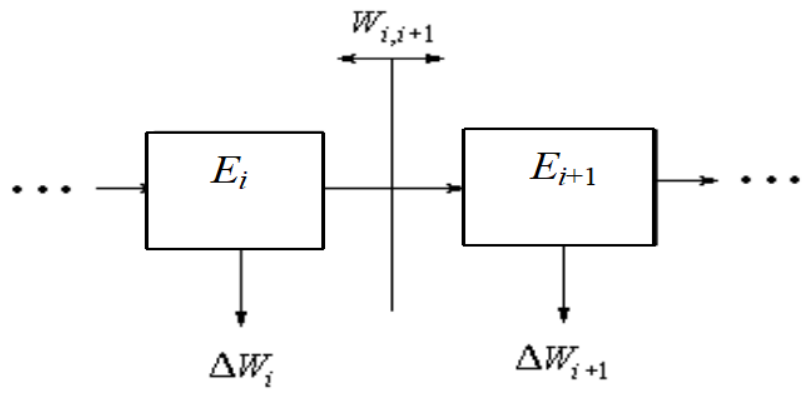

Рис. 3 Енергетичний канал електропривода

Корисна механічна робота, реалізована електроприводом, пов'язана такими процесами:

- зміною потенційної енергії технологічного об'єкта;

- зміною кінетичної енергії об'єкта;

- зміною внутрішньої енергії об'єкта;

- зміною геометричних розмірів об'єкта [8].

Технологія виконання корисної роботи і параметри елементів силового каналу електропривода визначають кількість енергії $W_{i, i+1}$, якою обмінюються "сусідні" елементи, і кількість енергії, що втрачається в кожному елементі $\Delta W_{j}[9]$.

Визнання корисною не лише енергії, переданої від джерела до механізму, що виконує механічну роботу (підйом вантажу), але й енергії, що надходить від механізму (спуск); точна вказівка перетину енергетичного каналу $(\mathrm{i}, \mathrm{i}+1)$, для якого виробляється оцінка ефективності; елементів каналу, у яких враховуються втрати; інтервалу часу, для якого справедлива оцінка, дозволили одержати узагальнений критерій у такому вигляді

$$
H=\frac{W_{i, i+1}}{W_{i, i+1}+\sum_{j} \Delta W_{j}},
$$

де $W_{i, i+1}=\int_{t_{1}}^{t_{1}+\tau} P_{i, i+1}(t) d t$ - енергії обміну між сусідніми елементами силового каналу за період оцінки, обумовлені даним режимом і параметрами каналу; $\left|P_{i, i+1}(t)\right|$ - модуль потужності цього потоку енергії; 
$\sum_{j} \Delta W_{j}=\sum_{j} \int_{t_{1}}^{t_{1}+\tau} \Delta P_{j}(t) d t-$ сумарні втрати енергії у вибраних $j$ елементах силового каналу; $P_{i, i+1}(t)$ - корисна потужність, що проходить через $i, i+1$ перетин енергетичного каналу; $\Delta P_{j}(t)$ - втрати потужності в $j$-мy елементі; $t_{1}, \tau$ - початок і кінець часового інтервалу, в окремому випадку $t_{1}=0$ i $\tau$ - час циклу.

Визначимо, наприклад, узагальнений показник для статичних режимів двигуна постійного струму незалежного збудження (рис. 4).
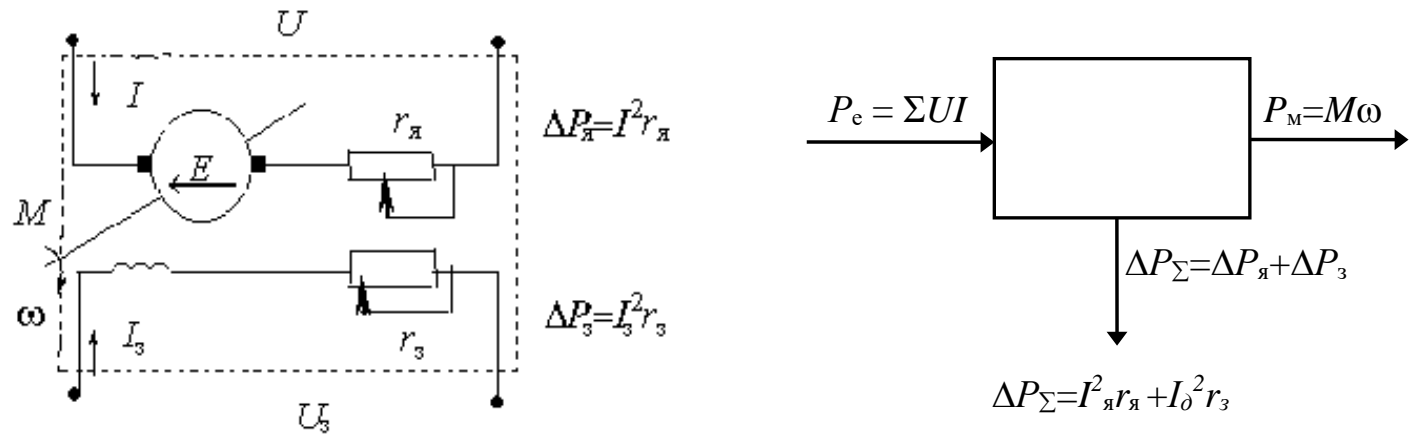

Рисунок 4 - Схема двигуна постійного струму незалежного збудження

Візьмемо до уваги лише втрати в двигуні, обумовлені тепловим розсіюванням енергії в якірному колі. Баланс потужностей для статичного режиму якірного кола двигуна визначається рівністю

$$
U I=M \omega+I^{2} r_{\text {я }},
$$

де $U I=P_{\mathrm{e}}$ - електрична потужність на вході двигуна (споживана); $P_{\mathrm{M}}=M \omega-$ механічна; $I^{2} r_{\mathrm{q}}-$ втрати в якірному колі.

Енергія, споживана по колі збудження, у процесі перетворення енергії не бере участі, вона необхідна лише для підтримки магнітного потоку машини.

Зв'язок між швидкістю і моментом двигуна

$$
\omega=\frac{U I-I^{2} r_{\mathrm{r}}}{M},
$$

або з урахуванням $M=k \Phi I$, механічна характеристика (рис. 5)

$$
\omega=\frac{U}{k \Phi}-\frac{M r_{\mathrm{q}}}{(k \Phi)^{2}},
$$

де $\omega_{0}=\frac{U}{k \Phi} ; M_{\text {кз }}=k \Phi I_{\text {к3 }} ; I_{\text {к3 }}=\frac{U}{r_{\text {я }}}$. 


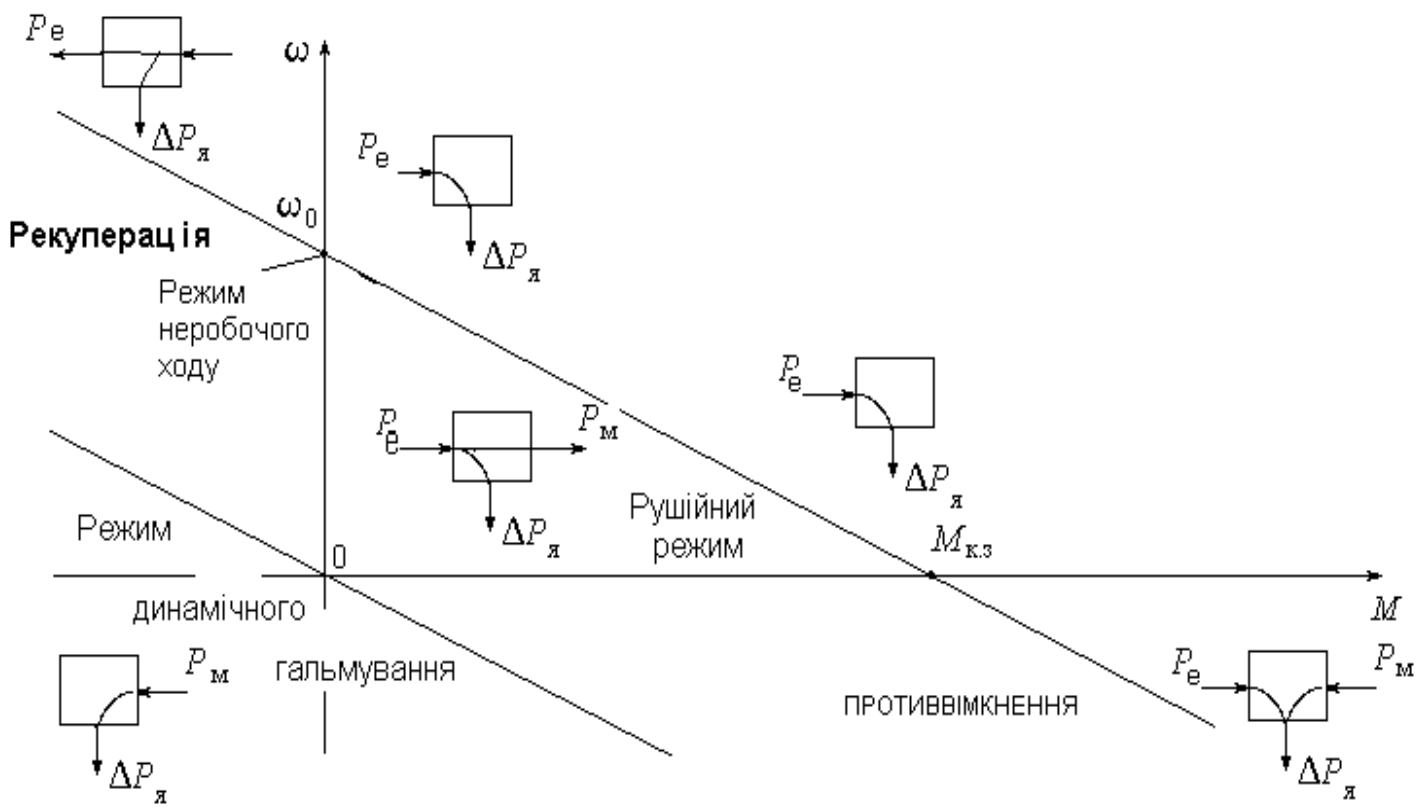

Рисунок 5 - Механічна характеристика двигуна постійного струму незалежного збудження

Приймемо в першому випадку $W_{i, i+1}$ як енергію на електричному вході машини

$$
W_{i, i+1}=\int_{t_{1}}^{t_{1}+\tau} U I d t,
$$

в другому - як енергію на механічному вході

$$
W_{i, i+1}=\int_{t_{1}}^{t_{1}+\tau} M \omega d t .
$$

Оцінюючи значення узагальненого критерію для статичних режимів, замість енергії $W_{i, i+1}$ підставимо відповідні потужності. При цьому потужність втрат у якорі

$$
\Delta P_{\text {я }}=I^{2} r_{\text {я }}=U I-M \omega=M\left(\omega_{0}-\omega\right) \text {. }
$$

Стосовно електричного і механічного входів одержимо відповідно

$$
\begin{gathered}
H_{\mathrm{e}}=\frac{|U I|}{|U I|+\left|M\left(\omega_{0}-\omega\right)\right|}=\frac{\left|M \omega_{0}\right|}{\left|M \omega_{0}\right|+\left|M\left(\omega_{0}-\omega\right)\right|}, \\
H_{\mathrm{M}}=\frac{|M \omega|}{|M \omega|+\left|M\left(\omega_{0}-\omega\right)\right|} .
\end{gathered}
$$

Залежності $H_{\mathrm{e}}(\omega)$ і $H_{\mathrm{m}}(\omega)$ показані на рис. 6 .
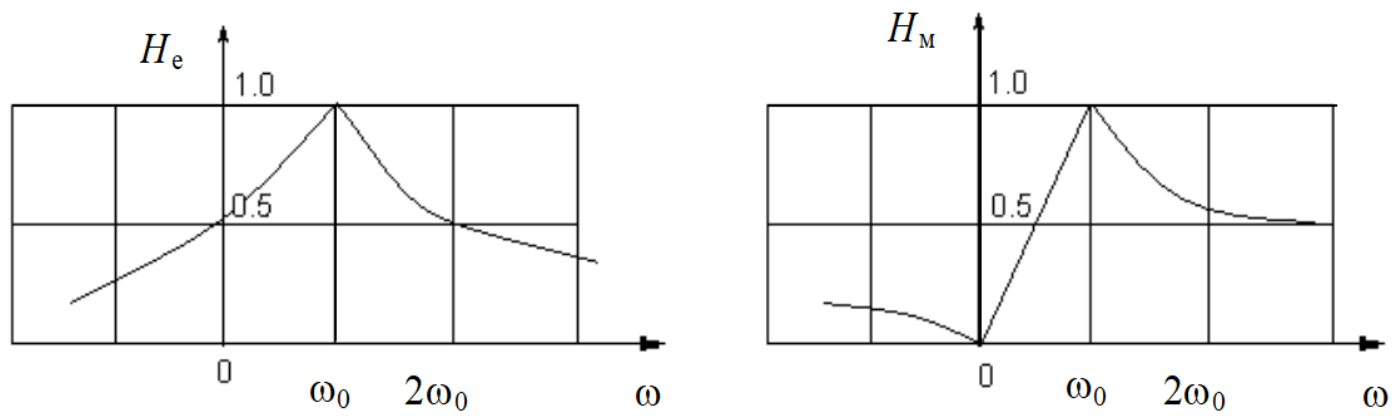

Рисунок 6 - Залежності коефіцієнтів $H_{\mathrm{e}}(\omega)$ і $H_{\mathrm{m}}(\omega)$ 


\section{ISSN 1813-5420 (Print). Енергетика: економіка, технології, екологія. 2017. № 4}

Коефіцієнт $H_{\mathrm{e}}$ оцінює ефективність двигуна як споживача енергії, а $H_{\mathrm{m}}$ - як перетворювача енергії. Проаналізуємо їх зміну для характерних режимів двигуна.

Для прийнятих умов $\left(\Delta P_{\mathrm{B}}=0\right)$ у режимі вільного ходу, тобто при $\omega=\omega_{0} H_{\mathrm{e}}=H_{\mathrm{M}}=1$, оскільки втрати дорівнюють нулю. У рекуперативному режимі $\left(\omega>\omega_{0}\right)$ обидва показники знижуються, причому ефективність машини стосовно мережі $H_{\mathrm{e}}$ падає швидше, ніж $H_{\mathrm{m}}$. У рушійному режимі $0<\omega<\omega_{0}$ значення $H_{\mathrm{e}}$ і $H_{\mathrm{m}}$ знижуються, однак значення $H_{\mathrm{м}}$ знижується швидше, приймаючи при $\omega=0$ значення $H_{\mathrm{m}}=0$, а $H_{\mathrm{e}}=0,5$. При $\omega<0$ значення $H_{\mathrm{m}}$ зростає до 0,5 , а $H_{\mathrm{e}}$ прагне до нуля (режим противвімкнення). Для режиму динамічного гальмування $H_{\mathrm{e}}=0$ (двигун не зв'язаний з мережею $P_{\mathrm{e}}=0$ ), а $H_{\mathrm{m}}=0,5$, оскільки завжди $\Delta P_{\mathrm{q}}=P_{\mathrm{M}}$.

При урахуванні постійних втрат (не залежних від режиму роботи силового каналу) жоден 3 показників не може досягти значення рівного одиниці. При будь-якій фізичній реалізації системи втрати неминучі. Найбільшому значенню $H$ повинні відповідати найменші втрати енергії

$$
\Delta W_{\Sigma}=\int_{0}^{T} \Delta P_{\Sigma} d t \rightarrow \min ,
$$

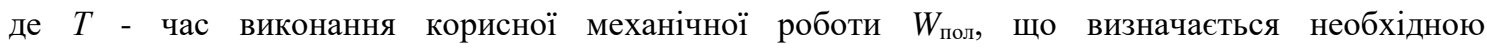
продуктивністю.

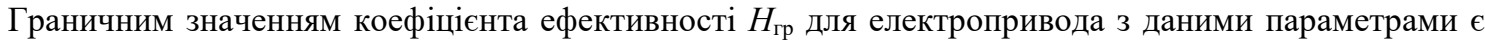
його значення при найменших можливих втратах $\Delta W^{\prime}$, відповідних виконанню заданої роботи при $P_{i, i+1}=$ const i $W_{\text {пол }} / T=P_{\text {пол }}=$ const. Наприклад, для перетину “робочий орган - технологічний об'єкт"

$$
H_{\text {пр }}=\frac{W_{\text {пол }}}{W_{\text {пол }}+\Delta W_{\Sigma}^{\prime}} .
$$

Висновок. Щоб вирішити, яка система електропривода в енергетичному відношенні має перевагу, чи всі елементи силового каналу цілком завантажені, наскільки вдало обрано спосіб керування, як електропривод взаємодіє з джерелом енергії, необхідно застосувати узагальнений показник енергетичної ефективності електропривода. Розглянутий спосіб визначення енергетичних індикаторів електропривода на основі узагальненого показника дозволяє більш повно і точно оцінити його енергетичний стан в порівнянні з традиційними ККД та $\cos \varphi$, а також враховує властивості електропривода як перетворювача та споживача енергії.

\section{Список використаної літератури.}

1. Ермолаев С.А. Эксплуатация энергооборудования в сельском хозяйстве / С.А. Ермолаев, Е.П. Масюткин, В.Ф. Яковлев. - Киев: Фирма "Инкос", 2005. - 670 с.

2. И. Я. Браславский. Энергосберегающий асинхронный электропривод / И. Я. Браславский, З.И. Ишматов, В.Н. Поляков. - Москва, Academa 2004, 256 с.

3. Закладний О.М. Електропривод: навч. посіб. / О.М. Закладний, В.В. Прокопенко, О.О. Закладний. -К.: НТУУ «КПІ», 2007. - 316 с

4. П.В. Тютева Оценка стоимости асинхронных двигателей при изменении геометрии поперечного сечения / П.В. Тютева, О.О. Муравлева // Известия Томского политехнического университета. 2010. Т. 316. № 4, c.183-186

5. Д.И. Родькин. Системы динамического нагружения и двагностики электродвигателей при послеремонтных испытаниях / Д.И. Родькин - М.: недра, 1992. - 236 с.

6. Закладний О.О. Методика функціонального діагностування енергоефективності асинхронного електропривода. Енергетика: економіка, технології, екологія. 2013. №1, с. 79-84.

7. Сыромятников И.А. Режимы работы асинхронных и синхронных двигателей / И.А. Сыромятников; под ред. Л.Г. Мамиконянца. - 4-е изд., переработ. и доп. - М.: Энергоатомиздат, 1984. $240 \mathrm{c}$.

8. Котеленец Н.Ф. Испытания, эксплуатация и ремонт электрических машин: Учебник для вузов / Н.Ф. Котеленец, Н.А. Акимова, М.В. Антонов. - М.: Издательский центр “Академия”, 2003. - 384 с. 
O. Zakladnyi, Cand.Sc. (Eng.), Assoc. Prof., ORCID 0000-0003-2813-3692

V. Prokopenko Cand.Sc. (Eng.), Assoc. Prof., ORCID 0000-0002-5518-5802

National Technical University of Ukraine

"Igor Sikorsky Kyiv Polytechnic Institute"

GENERALIZED INDEX OF ENERGY EFFICIENCY OF ELECTRIC DRIVE

The article deals with the methodological basis for determining the generalized indicator as a criterion for the efficiency of the process of electromechanical energy conversion by an electric drive, the use of which is necessary for the energy optimization of the electric drive. The balance of the power fluxes for the power channel of the electric drive, the efficiency of the serial energy channel and the example of calculating the generalized energy efficiency index of the power channel of the electric drive for the static conditions of the DC motor of independent excitation are given.

In order to decide which power system the power system has an advantage, whether all elements of the power channel are fully loaded, how well the chosen way of controlling how the electric motor interacts with the power source, it is necessary to apply a generic indicator of the energy efficiency of the electric drive. The considered method of determining the energy indicators of the electric drive on the basis of the generalized indicator allows more accurately and accurately estimate its energy status in comparison with the traditional efficiency and $\cos \varphi$, and also takes into account the properties of the electric drive as a converter and consumer of energy.

Key words: energy saving, energy efficiency index, electric drive, efficiency, electric balance.

\section{References}

1. Ermolaev S.A. Operation of power in agriculture / S.A. Ermolaev, E.P. Masyutkyn, V.F. Yakovlev. Kiev: Fyrma "Ynkos", 2005. - 670 p.

2. Y. Ya. Braslavskyy. Energy-saving asynchronous electric drive/ Y. Ya. Braslavskyy, Z.Y. Yshmatov, V.N. Polyakov. - Moskva, Academa 2004, 256 p.

3. Zakladnyi O.M. Electric drive: teach. guidance / O.M. Zakladnyi, V.V. Prokopenko, O.O. Zakladnyi. K.: NTUU «KPI», 2007. - 316 p.

4. P.V. Tyuteva. Valuation of asynchronous motors when changing the cross-sectional geometry / P.V. Tyuteva, O.O. Muravleva // Yzvestyya Tomskoho polytekhnycheskoho unyversyteta. 2010. V. 316. \# 4, p.183186

5. D.Y. Rod'kyn. Systems of dynamic loading and diagnostics of electric motors with post-repair tests / D.Y. Rod'kyn - M.: Nedra, 1992. - 236 p.

6. Zakladnyi O.O. Methods of functional diagnostics asynchronous electric energy. Enerhetyka: ekonomika, tekhnolohiyi, ekolohiya. 2013. \#1, p. 79-84.

7. Syromyatnykov Y.A. Modes of operation of asynchronous and synchronous motors / Y.A. Syromyatnykov; edited by L.H. Mamykonyantsa. - 4th ed. revised and enlarged. - M.: Energoatomisdat, 1984. $240 \mathrm{p}$.

8. N.F. Kotelenets, N.A. Akimova, and M.V. Antonov, Tests, operation and repair of electric machines: Textbook for high schools, Moscow, Russia: Publishing Center "Academy", 2003.

УДК 621.311.001.57(063)

O.А. Закладной, канд. техн. наук, доцент, ORCID 0000-0003-2813-3692

B.B. Прокопенко, канд. техн. наук, доцент, ORCID 0000-0002-5518-5802

Национальный технический университет Украины «Киевский политехнический институт имени Игоря Сикорского» ОБОБЩЕННЫЙ ПОКАЗАТЕЛЬ ЭНЕРГЕТИЧЕСКОЙ ЭФФЕКТИВНОСТИ ЭЛЕКТРОПРИВОДА

В статье рассматриваются методические основы определения обобщенного показателя как критерия эффективности прочесса электромеханического преобразования энергии электроприводом, использование которого необходимо для энергетической оптимизации электропривода. Приведень баланс мощиостей потоков энергии для энергетического канала электропривода, КПД последовательного энергетического канала $u$ пример расчета обобщенного показателя энергоэффективности энергетического канала электропривода для статических режимов двигателя постоянного тока независимого возбуждения.

Ключевые слова: энергосбережение, показатель энергоэффективности, электропривод, Коэффициент полезного действия, электрический баланс. 